\title{
Instrumento de avaliação de fala para análise acústica (IAFAC) baseado em critérios linguísticos
}

\author{
Speech evaluation instrument for acoustical analysis based \\ on linguistic criteria
}

\author{
Larissa Cristina Berti ${ }^{1}$, Alessandra Pagliuso ${ }^{2}$, Francine Lacava ${ }^{3}$
}

\begin{abstract}
RESUMO
Objetivo: Elaborar um instrumento de avaliação da fala de crianças, que contemple todos os fonemas consonantais do Português Brasileiro, para viabilizar o uso de uma metodologia instrumental. Métodos: A escolha das palavras foi baseada em critérios linguísticos do Português Brasileiro (PB), previamente definidos, pesquisados no banco de dados fônico-lexicais - CETENFolha, relativos: à classe gramatical, ao número de sílabas, ao acento e ao padrão silábico a partir da ocorrência das palavras-tipo. Resultados: Com base nos critérios linguísticos o instrumento foi composto por 96 palavras que contemplavam pelo menos três ocorrências de todos os fonemas consonantais do PB que acompanhavam as vogais /i,a,u/ na posição acentuada. Dentre as palavras do instrumento houve a prevalência de substantivos dissílabos paroxítonos. Quanto ao padrão silábico, 57 palavras iniciavam com padrão silábico simples e 39 palavras envolviam a produção de padrão silábico complexo. Conclusão: O presente trabalho não só forneceu critérios linguísticos para elaboração de instrumentos de avaliação de produção e/ou percepção de fala, como também disponibilizou um instrumento de avaliação de fala para uso de uma metodologia instrumental para o campo da Fonoaudiologia.
\end{abstract}

Descritores: Avaliação; Fala; Acústica; Crianças

\section{INTRODUÇÃO}

Crianças que apresentam problemas de produção de fala são frequentemente encaminhadas para avaliação e tratamento fonoaudiológico. Em vista disso, nesta área, existem alguns instrumentos elaborados para avaliação da fala das crianças com base em diferentes critérios linguísticos.

Dentre os principais instrumentos padronizados de avaliação de fala das crianças falantes do Português Brasileiro (PB) existentes na Fonoaudiologia, destacam-se: a Avaliação Fonológica da Criança $^{(1)}$; a Avaliação de base Fonológica ${ }^{(2)}$; e o teste de linguagem infantil $\mathrm{ABFW}^{(3)}$.

O instrumento de Avaliação Fonológica da Criança ${ }^{(1)}$, por exemplo, tem como principal critério linguístico de escolha

Trabalho realizado no Departamento de Fonoaudiologia da Universidade Estadual Paulista "Júlio de Mesquita Filho" - UNESP - Marília (SP), Brasil. (1) Doutora, Bolsista Jovem Pesquisador da Fundação de Amparo à Pesquisa do Estado de São Paulo - FAPESP, vinculada ao Departamento de Fonoaudiologia da Universidade Estadual Paulista "Júlio de Mesquita Filho" - UNESP - Marília (SP), Brasil.

(2) Graduanda em Fonoaudiologia pela Universidade Estadual Paulista "Júlio de Mesquita Filho" - UNESP - Marília (SP), Brasil.

(3) Fonoaudióloga graduada pela Universidade Estadual Paulista "Júlio de Mesquita Filho" - UNESP - Marília (SP), Brasil.

Endereço para correspondência: Larissa Cristina Berti. R. Antônio Lorencil

Serafim, 116, Marília (SP), Brasil, CEP: 17514-600.

E-mail: larissa.berti@uol.com.br

Recebido em: 19/5/2008; Aceito em: 31/3/2009 das palavras a discriminação de quatro posições dos fones contrastivos do PB: ISIP (início de sílaba início de palavra), ISDP (início de sílaba dentro da palavra), FSDP (final de sílaba dentro da palavra) e FSFP (final de sílaba final da palavra). De modo semelhante, a Avaliação de base Fonológica ${ }^{(2)}$ propõe que a escolha das palavras deve ser feita considerando as mudanças de posições - inicial e final das palavras - dos fones contrastivos do PB. E, por fim, o teste de linguagem infantil $\mathrm{ABFW}^{(3)}$ averigua não somente todos os fonemas contrastivos do $\mathrm{PB}$, nas posições inicial e final, como também leva em conta a estrutura silábica (CV e CCV).

Com efeito, todos estes instrumentos não somente direcionam a investigação da produção de fala das crianças por análises, guiadas pela outiva dos investigadores, como também a descrição e interpretação da fala dessas crianças são baseadas em unidades fonológicas fundamentalmente categóricas e abstratas (como, por exemplo, no fonema, processos fonológicos ou traços distintivos).

Ressalta-se, porém, que a utilização exclusiva da análise de outiva para a caracterização de fenômenos fônicos tem sido fortemente questionada, na medida em que alguns estudos têm demonstrado que análises instrumentais podem evidenciar diferenças entre produções julgadas como idênticas em uma análise de outiva ${ }^{(4-14)}$.

Entretanto, o uso de um recurso instrumental - acústica e/ou articulatória - para avaliação da produção de fala das 
crianças requer alguns cuidados na escolha das palavras, principalmente no que se refere ao contexto fonéticofonológico, além da necessidade de controlar o contexto prosódico de ocorrências dessas palavras.

No tocante ao contexto fonético-fonológico das palavras, tanto o contexto vocálico quanto o contexto consonantal precisam ser considerados. Em relação ao contexto vocálico, muitos estudos apontaram para a necessidade de ser levada em conta a vogal que acompanhará o segmento a ser analisado acusticamente, na medida em que a produção de fala varia enormemente em função da vogal adjacente. Por exemplo, a análise acústica da produção do /s/ varia em função da vogal que acompanha este segmento ${ }^{(15-18)}$.

Analogamente, os segmentos consonantais adjacentes também precisam ser levados em conta, na medida em que coarticulações* antecipatórias e/ou perseveratórias estão presentes na produção da fala. Como ilustração, em uma descrição preliminar ${ }^{(19)}$ a respeito da coarticulação perseveratória consoante-vogal no PB, este autor observou que consoantes como /p, t, k/ influenciam diferentemente as vogais /i, a, u/.

Adicionalmente, também se faz necessário considerar o padrão acentual de ocorrência do segmento a ser analisado, uma vez que, conforme a tonicidade da sílaba, parâmetros acústicos como a duração, frequência e intensidade podem ser modificados ${ }^{(20-21)}$.

Quanto ao contexto prosódico de ocorrências das palavras, vários estudos ${ }^{(18,22-23)}$ apontam para a necessidade do uso de frase veículo** para análise acústica ao invés de palavras isoladas, para se obter um maior controle da estrutura prosódica das sentenças, isolando com mais rigor o segmento a ser analisado, propiciando posteriormente a realização de análise estatística.

Desse modo, o uso da análise acústica das produções de fala de crianças é um recurso instrumental indispensável não somente para pesquisa como também para a prática clínica fonoaudiológica, o que viabiliza caracterizar e quantificar as tentativas dessas crianças em marcar um determinado contraste fônico que podem não ser percebidas via análise de outiva.

Neste contexto, o presente trabalho objetiva elaborar e disponibilizar um instrumento de avaliação da fala de crianças com base em critérios linguísticos, que contemple todos os fonemas consonantais do PB, servindo como um protocolo para o levantamento de dados empíricos para posterior análise acústica.

\section{MÉTODOS}

A escolha das palavras foi baseada em critérios linguísticos do $\mathrm{PB}$ previamente definidos, pesquisados no banco de dados fônico-lexicais - CETENFolha, composto pela ocorrência de 24 milhões de palavras distribuídas por cerca de 220.000 tipos, disponibilizado pelo LAFAPE****
O banco de dados fônicos-lexicais do CETENFolha trata-se de uma amostra de 24 milhões de palavras do jornal "A Folha de São Paulo", coletada e tratada pelo Núcleo Interinstitucional de Linguística Computacional (NILC), da Universidade de São Paulo, e disponibilizada pela Linguateca, sítio interinstitucional de Internet sediado em Portugal e dedicado ao estudo do processamento computacional da língua portuguesa.

Os critérios linguísticos pesquisados no CETENFolha foram relativos: à classe gramatical, ao número de sílabas, ao acento e ao padrão silábico a partir da ocorrência das palavras-tipo $^{* * * *}$.

De acordo com a classe gramatical pesquisada no banco de dados do CETENFolha, houve um predomínio de substantivos $(61,6 \%)$ em detrimento aos adjetivos, verbos, advérbios, etc., conforme demonstra a Figura 1.

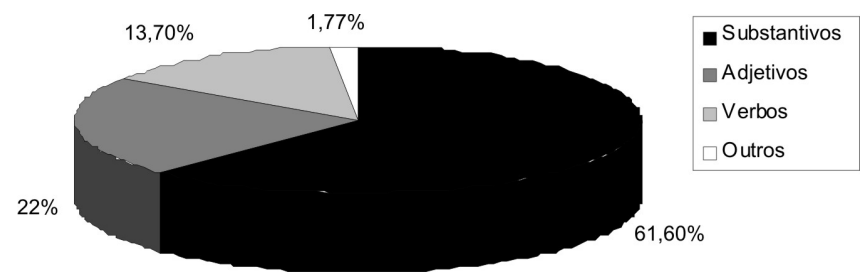

Figura 1. Distribuição da classe gramatical das palavras-tipo do banco CETENFolha

Quanto ao número de sílabas das palavras-tipo consultados no CETENFolha, houve uma maior percentagem de trissílabos $(35,62 \%)$ seguidos de tetrassílabos $(26,17 \%)$ e dissílabos $(19,82 \%)$, conforme ilustra a Figura 2.

Vale a pena ressaltar que embora se tenha como forma canônica para o PB os dissílabos, este corpus se diferencia, provavelmente por ter como fonte a linguagem escrita formal culta.

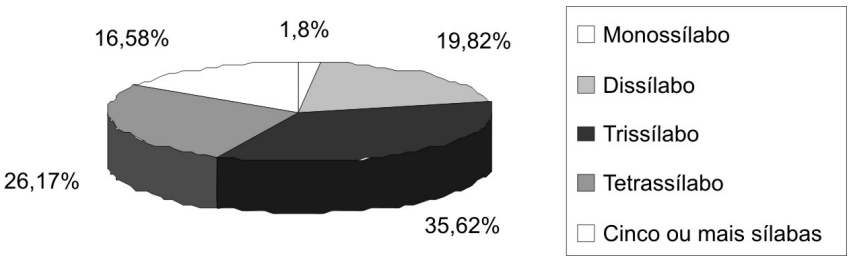

Figura 2. Distribuição do número de sílabas das palavras-tipo do banco CETENFolha

Em relação ao padrão acentual, os paroxítonos se apresentaram como a grande maioria do banco CETENFolha, computando um percentual de 59,52\% das palavras-tipo, conforme a Figura 3.

Por fim, no tocante ao padrão silábico (isto é, padrões que são definidos em função do tipo de segmento que compõe a sílaba), observamos apenas os padrões silábicos que iniciavam as palavras-tipo do banco CETENFolha. Os padrões silábicos

\footnotetext{
* Em termos tradicionais, define-se coarticulação como a influência entre segmentos discretos de fala. A coarticulação antecipatória ocorre quando os segmentos à direita influenciam os anteriores e a coarticulação perseveratória ocorre quando os segmentos à esquerda influenciam os seguintes.

** Um exemplo de frase-veículo a ser utilizada na análise acústica seria "Fale (palavra alvo) pra ele".

${ }^{* * * *}$ Refere-se ao Laboratório de Fonética e Psicolinguística Experimental situado no Instituto de Estudos da Linguagem da Universidade Estadual de Campinas - UNICAMP - Campinas (SP), Brasil, com tradição em pesquisa há mais de15 anos.

***** Engloba todas as palavras que ocorreram no Banco CETENFolha sem levar em conta as respectivas frequências de ocorrência
} 

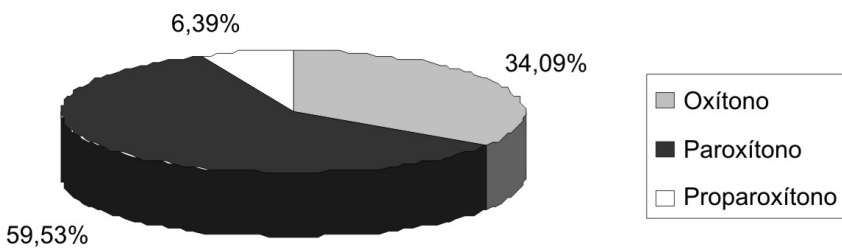

Figura 3. Distribuição do padrão acentual das palavras-tipo do banco CETENFolha

foram classificados e divididos em duas categorias principais: padrão silábico simples e padrão silábico complexo ${ }^{(24)}$. Essa divisão foi feita considerando que, quanto maior o número de elementos envolvidos na constituição de uma sílaba, maior sua complexidade estrutural.

Desse modo, foi considerado como padrão silábico simples aquele que era composto por apenas uma vogal $(\mathrm{V})$, ou então aquele que era composto por uma consoante seguida de uma vogal (CV). Analogamente, o padrão silábico complexo referia-se às estruturas silábicas que contemplavam, por exemplo, os grupos consoanantais (CCV) e as codas (CVC).

Constatou-se que a maioria das palavras-tipo iniciava com padrão silábico simples, isto é, vogal (V) ou então consoantevogal (CV) (56,19\%), seguido de padrão silábico complexo $(44,97 \%)$, isto é, consoante-consoante-vogal $(8,23 \%)$ ou consoante-vogal-consoante $(35,53 \%)$, tal como representa a Figura 4.

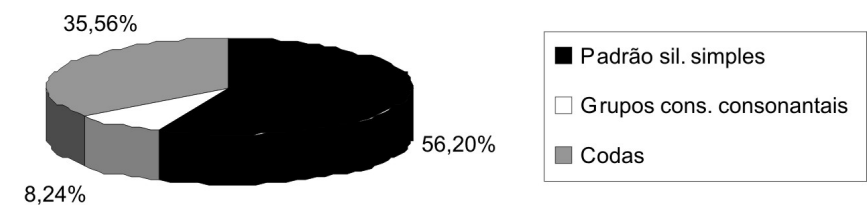

Figura 4. Distribuição do padrão silábico inicial das palavras-tipo do banco CETENFolha

Com base nos critérios linguísticos consultados no banco de dados CETENFolha, privilegiou-se escolher palavras para compor o instrumento que seguissem, na medida do possível, os critérios anteriormente investigados.

Além disso, conforme exposto na introdução deste trabalho, também considerou-se o contexto fonético-fonológico das palavras, uma vez que o contexto vocálico, bem como os sons adjacentes ao segmento a ser analisado acusticamente, influenciam enormemente a sua produção.

No tocante ao contexto vocálico, privilegiou-se a ocorrência dos fonemas consonantais seguidos das vogais /i, a, $\mathrm{u} /$ pelo fato de que ao conjunto dessas vogais correspondem os extremos do triangulo vocálico. Ou seja, a vogal/i/ corresponde à vogal mais anterior e mais alta; a vogal /a/ corresponde à vogal mais baixa e central, e por fim, a vogal $/ \mathrm{u} /$ corresponde à vogal mais alta e mais posterior do PB.

Ressalta-se, especialmente, quando o padrão silábico envolvia a presença de coda silábica, ou seja, padrão silábico CVC, as vogais /i, a, u/, antecederam, obviamente, a segunda consoante.
Em relação ao contexto consonantal, ou seja, às consoantes adjacentes, privilegiou-se a ocorrência de segmentos pertencentes à classe das obstruintes e, no interior desta classe, privilegiou-se, na medida do possível, a ocorrência das bilabiais, na tentativa de minimizar os efeitos coarticulatórios. Além disso, evitou-se a possibilidade de ocorrência de qualquer consoante nasal, impedindo desse modo, que a vogal se tornasse nasalizada ${ }^{* * * * *}$.

Com base nestes critérios linguísticos descritos, arrolou-se palavras para compor o instrumento proposto e, posteriormente, buscou-se por meio do site http://www.images.google.com. br/ de domínio público, as figuras que representassem direta ou indiretamente as palavras alvos. Com o auxílio do software Paint, recortou-se e editou-se as imagens, de modo a padronizálas ao seu tamanho para que pudessem ser dispostas em cartões.

A seguir, será apresentado o conjunto de palavras que compõem o instrumento de avaliação de fala para análise acústica (IAFAC).

\section{RESULTADOS}

Esse instrumento foi elaborado para ser utilizado na coleta de dados relativos à produção de fala - possibilitando, posteriormente, a realização de análise acústica de tais dados - de crianças a partir de três anos de idade, pertencentes a diferentes classes sociais.

Com base nos critérios linguísticos anteriormente apresentados, o instrumento de avaliação de fala para análise acústica foi composto por 96 palavras passíveis de representação por meio de gravuras. Nem todas as palavras escolhidas eram passíveis de representação. Desse modo, também foram utilizadas palavras que seriam identificadas indiretamente.

Tais palavras contemplaram pelo menos três ocorrências de todos os fonemas consonantais do PB acompanhados das vogais /i, a, u/ na posição acentuada. Em todos os fonemas, estas vogais os seguiam. No caso das codas, estas vogais antecederam, obviamente, o segmento que ocupava a posição de coda silábica.

Em relação ao contexto consonantal, ou seja, às consoantes adjacentes, privilegiou-se a ocorrência de segmentos pertencentes à classe das obstruintes e, no interior desta classe, na medida do possível, a ocorrência das bilabiais, na tentativa de minimizar os efeitos coarticulatórios.

No entanto, não foi possível manter a mesma consoante adjacente nos três contextos vocálicos para todas as palavras, devido à dificuldade de escolha de palavras passíveis de representação por meio de gravuras (direta ou indiretamente). Um exemplo dessa dificuldade refere-se à posição de coda nasal e não lateral, onde foi priorizada a escolha das seguintes palavras: "pinta", "santo", "bumbo", "circo", "carta" e "curto", respectivamente.

Em relação à classe gramatical, houve uma prevalência de substantivos (89,59\%), seguidos de adjetivos (10,41\%).

Quanto ao padrão acentual, todas as palavras selecionadas foram vocábulos paroxítonos.

**** A única exceção foi a escolha da palavra "prumo", pelo fato de não ter sido encontrada nenhuma outra palavra que obedecesse aos critérios previamente estabelecidos. 
Com relação ao número de sílabas, o instrumento foi composto por 85 palavras dissilábicas $(88,54 \%)$ e 11 palavras trissilábicas $(11,46 \%)$.

No que se refere ao padrão silábico, 57 palavras envolviam a produção de padrão silábico simples $(59,37 \%)$ e 39 palavras, de padrão silábico complexo $(40,62 \%)$. Ressalta-se, porém, que dentre as 57 palavras envolvendo a produção de padrão silábico simples, 48 palavras iniciavam-se com o padrão silábico simples e, apenas nove palavras o padrão silábico a ser analisado encontrava-se no meio da palavra. Isso ocorreu pelo fato do PB não conter palavras que se iniciam, por exemplo, com tepe e pouquíssimas palavras que se iniciam com lateral e nasal palatais.

Da mesma forma, dentre as 39 palavras que envolviam a produção do padrão silábico complexo, 37 palavras iniciavamse com o padrão silábico complexo, enquanto apenas duas palavras este padrão encontrava-se no meio da palavra, como por exemplo, nas palavras: "nublado" e "aplique", devido ao fato de não haver outro exemplo passível de representação por meio de gravuras.

Ainda, em relação ao padrão silábico complexo, não foi contemplada a ocorrência de todos os grupos consonantais existentes no PB; privilegiamos apenas aqueles de maior frequência de ocorrência na língua ${ }^{(25)}$, excluindo, por exemplo, a ocorrência dos encontros /dr/ e /gl/, por sua baixíssima frequência de ocorrência no PB.

Os Quadros 1 e 2 apresentam a lista de palavras que compôs o instrumento de avaliação de fala para análise acústica.

No Quadro 1, estão dispostas as palavras que envolvem a produção do padrão silábico simples, enquanto que no Quadro 2 , são apresentadas as palavras que envolvem a produção de padrão silábico complexo.

No Anexo 1 estão dispostas todas as gravuras que representam, direta ou indiretamente, as palavras alvo do instrumento.

A seguir, encontram-se as instruções necessárias quanto aos procedimentos de aplicação do instrumento proposto.

\section{Informações sobre os procedimentos para aplicação do IAFAC}

\section{Faixa etária a ser avaliada}

Conforme mencionado na seção dos resultados, este instrumento foi elaborado para ser aplicado em crianças a partir de três anos de idade, com e sem problemas de produção de fala, pertencentes a diferentes classes sociais.

\section{Procedimento de aplicação do IAFAC}

Pelo fato de o instrumento ter sido elaborado para ser utilizado na coleta de dados relativos à produção de fala - possibilitando, posteriormente, a realização de análise acústica, torna-se imprescindível que o avaliador disponha de equipamentos de gravação de alta fidelidade ${ }^{* * * * * *}$, assim como de um ambiente silencioso e/ou uma cabina acústica.

Antes do início da aplicação do instrumento sempre se deve ter em mãos o consentimento livre e esclarecido (conforme
Quadro 1. Palavras que compõem o IAFAC, que envolvem a produção de padrão silábico simples

\begin{tabular}{|c|c|c|c|}
\hline Padrão silábico simples & /i/ & /a/ & /u/ \\
\hline$/ \mathrm{p} /$ & pipa & papa & pupa \\
/b/ & bico & bala & bule \\
/t/ & Tico* & taco & tuba \\
/d/ & dica* & dado & ducha \\
/k/ & quibe & capa & Cuca \\
/g/ & guizo & gato & gula \\
/v/ & viga & vaca & vuba \\
$/ \mathrm{f} /$ & fita & faca & fuça \\
$/ \mathrm{s} /$ & Cica & sapo & suco \\
$/ \mathrm{z} /$ & zíper & zaga & zurro \\
$/ \mathrm{J} /$ & chique & chave & chuva \\
$/ 3 /$ & jipe & jaca & juba \\
$/ \mathrm{R} /$ & rico & rabo & ruga \\
$/ / /$ & lixo & lata & lupa \\
$/ \mathrm{m} /$ & mico & mapa & mula \\
$/ \mathrm{n} /$ & nicho & nabo & nuca \\
$/ \mathrm{\eta} /$ & banhista & cunhado & banhudo \\
$/ \mathrm{N} /$ & filhinho & palhaço & olhudo \\
$/ \mathrm{r} /$ & coriza & barata & barulho \\
\hline
\end{tabular}

* Ressalta-se, que/t/e /d/ diante de /i/, podem sofrer fricatização dependendo do local (região, cidade brasileira) onde forem coletadas as amostras de produção de fala. Caso isso ocorra, estes sons deverão ser analisados separadamente, pertencendo à classe das africadas.

Quadro 2. Palavras que compõem o IAFAC que envolvem o padrão silábico complexo

\begin{tabular}{|c|c|c|c|}
\hline Padrão silábico complexo & /i/ & /a/ & $/ \mathrm{u} /$ \\
\hline$/ \mathrm{bl} /$ & blitz & nublado & blusa \\
$/ \mathrm{pl} /$ & aplique & placa & pluto \\
$/ \mathrm{kl} /$ & clipe & clave & clube \\
$/ \mathrm{pr} /$ & Prit & prato & prumo \\
$/ \mathrm{br} /$ & brilho & braço & bruxa \\
$/ \mathrm{kr} /$ & crivo & cravo & cruza \\
$/ \mathrm{gr} /$ & gripe & grade & gruta \\
$/ \mathrm{fr} /$ & frita & fraque & fruta \\
$/ \mathrm{tr} /$ & tribo & trave & truco \\
Coda lateral & filtro & salto & multa \\
Coda fricativa* & lista & pasta & susto \\
Coda não lateral* & circo & carta & curto \\
Coda nasal & pinta & santo & bumbo \\
\hline
\end{tabular}

* Vale a pena ressaltar que 0 avaliador deverá levar em conta as variações existentes nas produções destas codas dependendo do local em que os dados forem coletados. A coda fricativa pode ser produzida como fricativa surda alveolar ou palatal. A coda lateral, por sua vez, pode ser produzida como alveolar, de forma velarizada ou ainda de forma vocalizada. Finalmente, dentre as principais variações descritas na literatura para a coda não lateral, esta pode ser produzida como vibrante simples (tepe), fricativa velar, retroflexa alveolar, retroflexa palatal ou aproximante.

recomendações do Comitê de Ética em Pesquisa) assinado pelos pais e/ou responsáveis pelas crianças. Além disso, deve ser perguntado às crianças se querem ou não participar da gra-

\footnotetext{
** Recomenda-se como equipamentos de alta fidelidade o uso de gravadores digitais acoplados a microfones unidirecionais ou, então, um microcomputador contendo uma placa de som de alta qualidade.
} 
vação. No caso das crianças concordarem, mas se mostrarem um pouco encabuladas, a situação poderá ser contornada com alguns minutos de conversa e exploração do material que será utilizado na avaliação.

As palavras que compõem o instrumento, representadas por meio de gravuras, devem ser aleatorizadas e inseridas em uma frase veículo de fácil pronúncia, como, por exemplo, "Fale (palavra alvo) de novo".

É importante ressaltar, mais uma vez, a opção de se realizar as gravações por meio de repetições das frases veículos e não apenas das palavras isoladas, para tentar preservar a ocorrência das palavras alvos no mesmo contexto prosódico e fonético, tentando evitar, dessa maneira, possíveis modificações nos parâmetros acústicos (como, por exemplo, na duração).

As gravações deverão ser feitas com cada criança separadamente, em uma sala tratada acusticamente ou em uma sala silenciosa. Recomenda-se também, no momento da gravação, a utilização de um brinquedo (como fantoches, bonecos etc.) juntamente com as gravuras de cada uma das palavras que compõem instrumento aqui proposto.

A criança deverá ser disposta confortavelmente na sala de gravação, a uma distância aproximada de $15 \mathrm{~cm}$ do microfone.

A seguinte instrução poderá ser dada à criança: "Você agora irá entrar em uma nave espacial. Dentro dessa nave nós daremos início a uma brincadeira chamada de "robô falante". No visor da cabine, irá aparecer um robô que lhe mostrará algumas gravuras. Além disso, o robô também lhe dirá o nome de cada figura que ele estiver lhe mostrando. Irão aparecer diversas gravuras (nesse momento o avaliador deverá apresentar cada uma das figuras do IAFAC para a criança). Assim sendo, toda vez que o robô aparecer nesse visor, ele mostrará e dirá o nome de uma figura e você terá que dar uma ordem para ele. A ordem é a seguinte: "Fale (o nome da gravura que o robô mostrou) de novo". Como o robô é bem espertinho, ele não irá repetir o nome da gravura que você pediu; ao invés disso, ele irá mostrar uma nova gravura. Dessa forma, você terá que prestar bastante atenção".

Antes de iniciar a avaliação propriamente dita, o avaliador deverá realizar um treino com as crianças, no sentido de garantir a compreensão da tarefa a ser executada. Após essa etapa, o avaliador (por meio do material lúdico utilizado) dirá a palavra alvo como pista, com o apoio da gravura e solicitará das crianças a produção da frase veículo. As palavras deverão ser apresentadas de forma aleatória.

Caso a criança não consiga reproduzir a frase veículo na íntegra, pode-se mudar a frase veículo ou mesmo a estratégia de coleta*******.

O número de apresentações de cada gravura dependerá do objetivo do avaliador. Ou seja, caso o avaliador queira realizar somente uma inspeção acústica dos dados (procedimento indicado na realização de uma triagem), as gravuras devem ser apresentadas somente uma vez, obtendo-se desse modo, uma amostra de gravação de cada figura. O tempo estimado para a aplicação deste procedimento é de no máximo 20 a 30 minutos, a depender da idade da criança.

Se o objetivo do avaliador for realizar uma análise acústica propriamente dita dos dados, recomenda-se pelo menos cinco apresentações de cada uma das figuras, favorecendo, desse modo, uma análise estatística posterior. A fim de evitar o cansaço extremo por parte das crianças, comprometendo a aplicação do IAFAC, sugere-se a coleta dos dados em várias sessões de gravação.

No entanto, caso o avaliador queira utilizar este instrumento somente para uso clínico sem a necessidade de se atrelar pesquisa científica, pode ser feita somente uma repetição com a criança, propiciando uma inspeção acústica dos dados, ou seja, uma análise que não pressupõe análise estatística posterior.

Por fim, recomenda-se que as análises do sinal acústico devem ser feitas por meio do software livre PRAAT ${ }^{(26)}$, disponível para download no seguinte endereço eletrônico: www. praat.org.

\section{DISCUSSÃO}

Conforme exposto na seção anterior, o instrumento de avaliação de fala para análise acústica foi composto por 96 palavras representadas por meio de gravuras, que obedeceram aos critérios linguísticos previamente arrolados.

Em relação à classe gramatical, houve uma prevalência de substantivos $(89,59 \%)$, corroborando com o levantamento realizado com base no mini-dicionário Aurélio ${ }^{(27)}$.

Quanto ao padrão acentual, privilegiou-se a ocorrência de vocábulos paroxítonos, uma vez que diferentes pesquisas utilizando diferentes corpora têm apontado para este padrão acentual, como forma canônica do $\mathrm{PB}^{(25,27-28)}$. Ressalta-se, por exemplo, uma pesquisa realizada com base num corpus constituído por 2998 vocábulos $^{(28)}$, na qual constatou-se que os paroxítonos constituíram $63 \%$ do total dos vocábulos acentuados.

Com relação ao número de sílabas, o instrumento foi composto por 83 palavras dissilábicas $(86,45 \%), 11$ palavras trissilábicas $(11,45 \%)$ e duas palavras monossilábicas $(2,08 \%)$ concordando, mais uma vez, com pesquisas prévias que levantaram a prevalência do número de sílabas de vocábulos a partir de um corpus de referência ${ }^{(27-28)}$.

No que se refere ao padrão silábico, 57 palavras envolviam a produção de padrão silábico simples $(59,37 \%)$ e 39 palavras envolviam a produção de padrão silábico complexo (40,62\%), concordando com um levantamento realizado com base no mini-dicionário Aurélio ${ }^{(27)}$.

Adicionalmente, em relação ao contexto vocálico, a maioria das palavras contemplaram pelo menos três ocorrências de todos os fonemas consonantais do PB, acompanhados das vogais /i, a, u/ na posição acentuada e, especificamente, na posição de coda, estas vogais antecediam o segmento a ser analisado, seguindo os cuidados necessários para se realizar a análise acústica descritos na introdução deste trabalho.

Observa-se também que das 96 palavras, 64 foram representadas por meio de figuras que correspondiam diretamente

\footnotetext{
******** Sugere-se o uso de outras frases veículos, como: "Fale palavra alvo pra ele"; "Fale palavra alvo bem bonito", entre outras. Quanto à estratégia de coleta, também poderá ser solicitado da criança que ela ensine um "marciano", residente de uma nave espacial a falar, por meio da repetição de uma das frases veículos mencionadas.
} 
ao alvo, por exemplo, gravura de uma "bala" para representar a palavra ['bala], enquanto 32 palavras não se encontram diretamente representadas nas gravuras, por exemplo, a gravura de uma pessoa com um lenço no nariz para remeter a palavra [ko'riza]. Esse fato tem implicações diretas para o momento da coleta de dados. A principal implicação é que o experimentador precisará utilizar a procedimento de imitação retardada ${ }^{(1)}$, isto é, o experimentador precisará dizer para a criança qual é a palavra alvo que a figura corresponde, solicitando posteriormente a repetição desta palavra no interior da frase veículo. Vale a pena ressaltar que não tem sido observada diferença de desempenho das crianças com problemas de produção de fala em função do tipo de instrumento utilizado na avaliação, ou seja, se nomeação ou imitação ${ }^{(29)}$.

Além disso, há uma diferença de frequência de ocorrência no vocabulário infantil entre as palavras que compuseram o instrumento. Especificamente, há palavras possivelmente frequentes no vocabulário infantil, como por exemplo, "bala", "sapo", dentre outras; como também há palavras pouco ou nada frequentes no vocabulário infantil, como por exemplo, "pupa", "vuba", "zurro", dentre outras, implicando, mais uma vez, o uso do procedimento de imitação retardada por parte do experimentador no momento da coleta de dados.

Embora as palavras do instrumento apresentem esta discrepância de frequência de ocorrência no vocabulário infantil, optou-se pela manutenção das mesmas por três motivos: (a) por contemplarem todos os critérios linguísticos previamente definidos; (b) por não terem sido encontrados exemplos mais adequados que não só contemplassem os critérios linguísticos como também fossem passíveis de representação por meio de figuras; e (c) por não haver uma relação direta entre conhecimento lexical e produção de fala, conforme nossa interpretação do estudo que comparou provas de nomeação e imitação como instrumentos de diagnóstico do transtorno fonológico ${ }^{(29)}$.

Desse modo, optamos na manutenção das 96 palavras que obedeceram aos critérios linguísticos levantados.

Ressalta-se que a normatização deste instrumento vem sendo realizada em uma Escola Municipal de Educação Infantil da Cidade de Marília, por integrantes do Grupo de Pesquisa "Estudos sobre a Linguagem" (CNPq), em crianças com e sem desenvolvimento típico de linguagem.

Até o presente momento, todas as 100 crianças com desenvolvimento típico de linguagem, entre três e seis anos, de ambos os sexos, foram capazes de cumprir a tarefa proposta no uso do IAFAC. Ou seja, a partir da palavra alvo dita pelo avaliador como pista, as crianças foram capazes de repetir as frases veículos na íntegra, durante uma situação lúdica proposta no momento da coleta dos dados.

\section{CONCLUSÃO}

O presente trabalho não somente forneceu critérios linguísticos para elaboração de instrumentos de avaliação de produção e/ou percepção de fala, como também disponibilizou um instrumento de avaliação de fala que pode ser utilizado na coleta de dados relativos à produção de fala, viabilizando, a critério do avaliador, posterior análise acústica.

Ressalta-se, conforme exposto na introdução deste estudo, que o uso da análise acústica nas produções de fala de crianças requer vários cuidados no momento da coleta, na medida em que parâmetros de ordem linguística (como contexto vocálico, acento, padrão silábico, etc.) podem interferir enormemente na produção da fala.

Nesse sentido, o instrumento aqui proposto, com base em critérios linguísticos, além de corroborar com vários corpora do $\mathrm{PB}$, leva em conta as principais variáveis linguísticas que interferem na produção de fala. Esse fato viabiliza a coleta de dados de produção de fala em crianças, por profissionais que queiram utilizar a análise acústica não somente para pesquisa, como também para a prática clínica fonoaudiológica.

\section{AGRADECIMENTOS}

À Fundação de Amparo à Pesquisa do Estado de São Paulo (FAPESP), pelo apoio concedido no processo n ${ }^{\circ}$ 06/61816-4.

\begin{abstract}
Purpose: To elaborate a speech evaluation instrument for children contemplating all consonant sounds of Brazilian Portuguese, in order to make possible the use of an instrumental methodology. Methods: The selection of words was based on pre-defined linguistic criteria of the Brazilian Portuguese, searched on the CETENFolha Database. The linguistic criteria searched were: grammar class, number of syllables, stress and syllabic patterns. Results: Based on the linguistic criteria, the speech evaluation instrument comprised 96 words that contemplated at least three occurrences of all consonant phonemes of Brazilian Portuguese accompanying the vowels /i, a, u/ in stressed position. Among the words selected for the instrument, there was a prevalence of dissyllable nouns with the penultimate syllable stressed. Moreover, 57 words began with a simple syllabic pattern, and 39 words involved the production of a complex syllabic pattern. Conclusion: The present study not only provided linguistic criteria for the elaboration of speech production and/or perception evaluation instruments, but also made available a speech evaluation instrument for instrumental analysis in Speech-Language Pathology.
\end{abstract}

Keywords: Evaluation; Speech; Acoustics; Children 


\section{REFERÊNCIAS}

1. Yavas M, Hernandorena CLM, Lamprecht RR. Avaliação fonológica da criança: reeducação e terapia. Porto Alegre: Artes Médicas; 1992.

2. Lowe RJ. Fonologia: avaliação e intervenção: aplicações na patologia da fala. Porto Alegre: Artes Médicas; 1996.

3. Andrade CF, Befi-Lopes DM, Fernandes FDM, Wertzner HF. ABFW: teste de linguagem infantil nas áreas de fonologia, vocabulário, fluência e pragmática. Barueri: Pró-Fono; 2000.

4. Macken MA, Barton D. The acquisition of the voicing contrast in English: study of voice onset time in word-initial stop consonants. J Child Lang.1980;7(1):41-74.

5. Maxwell EM. The use of acoustic phonetics in phonological analysis. J Natl Student Speech Lang Hear Assoc. 1981;9:20-37.

6. Hewlett N. Acoustic properties of $/ \mathrm{k} /$ and $/ \mathrm{t} / \mathrm{in}$ normal and phonologically disordered speech. Clin Linguist Phon. 1988;2(1):29-45.

7. Scobbie JM, Wood SE, Wrench AA. Advances in EPG for treatment and research: an illustrative case study. Clin Linguist Phon. 2004;18(68):373-89.

8. Scobbie JM. Onset-rime coarticulation in the production of /dai/ and / stai/ by four-year-old Scottish English speaking children: preliminary results. Les Cahiers de l'ICP. Bull Commun Parlée. 2000;(5):131-41

9. Edwards J, Gibbon F, Fourakis M. On discrete changes in the acquisition of the alveolar/velar stop consonant contrast. Lang Speech. 1997;40(2):203-10.

10. Gibbon FE. Undifferentiated lingual gestures in children with articulation/phonological disorders. J Speech Lang Hear Res. 1999;42(2):382-97.

11. Scobbie JM, Gibbon F, Hardcastle WJ, Fletcher P. Covert contrast as a stage in the acquisition of phonetics and phonology. In: Broe MB, Pierrehumbert JB, editors. Acquisition and the lexicon. Cambridge: Cambridge University Press; 2000. Série: Papers in laboratory phonology. v.5, p. 194-207.

12. Hewlett N, Waters D. Gradient change in the acquisition of phonology. Clin Linguist Phon. 2004;18(6-8):523-33.

13. Berti LC. Um estudo comparativo de medidas acústicas em crianças com e sem problemas na produção de /s/ e /J/. Estudos Linguísticos. 2005;34:1337-42.

14. Rodrigues LL. O caráter exploratório das flutuações da fala infantil. Estud Linguíst. . 2006;35:1189-95.

15. Jesus LMT, Shadle CH. A parametric study of the spectral characteristics of European Portuguese fricatives. J Phon. 2002;30(3):437-64.

16. Munson B. Variability in /s/ production in children and adults: evidence from dynamic measures of spectral mean. J Speech Lang Hear Res. 2004;47(1):58-69.
17. Li F, Edwards J. Contrast and covert contrast in the acquisition of /s/ and $/ J /$ in English and Japonese. In: X International Conference on Laboratory Phonology, 2006 June 28-30; Paris. Proceedings [CD-ROM]. Paris: Labphon; 2006.

18. Berti LC. Gradiência na produção de fricativas coronais desvozeadas em crianças com e sem problemas de produção de fala: indício de uma construção do sistema fonológico. In: Pagni P, organizador. VI Simpósio em Filosofia e Ciência; 2005 Out. 4-7; Marília. Anais [CD-ROM]. FFC/ Marília/UNESP: Comissão Permanente de Publicações; 2005. ISBN 858673828-X.

19. Oliveira LCF. Estudo preliminar da coarticulação CV em português do Brasil: medidas de formantes. In: II Congresso Nacional da Abralin, 2000 Fev 25-27; Florianópolis. Anais [CD-ROM]. Florianópolis: ABRALIN; 2000; 2:1385-1394.

20. Massini-Cagliari G. Sobre a natureza fonética do acento em português. DELTA. 1993;9(2):195-216.

21. Consoni F, Arantes P, Barbosa PA, Ferreira Netto W. Hipóteses acerca do reconhecimento de acento lexical em palavras isoladas. Estud Linguíst. 2006;35:792-9.

22. Samczuk IB, Gama-Rossi AJA. Descrição fonético-acústica das fricativas no português brasileiro: critérios para coleta dos dados e primeiras medidas acústicas. Intercâmbio [CD-ROM]. 2004:13

23. Silva AHP, Clemente FC, Nishida G. Para a representação dinâmica do tap em grupos e codas: evidências acústicas. Revista Virtual de Estudos da Linguagem - ReVEL [CD-ROM]. 2006;4(7).

24. Cagliari LC. Elementos de fonética do Português Brasileiro. São Paulo: Paulistana Editora; 2007.

25. Albano EC. O gesto e suas bordas: esboço de fonologia acústicoarticulatória do português brasileiro. Campinas: Mercado de Letras; 2001.

26. Boersma P, Weenink D. Praat: doing phonetics by computer. [Programa de computador]. Compilado de http://www.praat.org/.

27. Gama-Rossi AJA, Silva A. Critérios linguísticos para a elaboração de listas de palavras no português brasileiro. Estud Linguíst [CD-ROM]. 2001;30(1).

28. Cintra G. Distribuição de padrões acentuais no vocábulo em português. Confluência. 1997;5(3):82-93.

29. Wertzner HF, Papp ACCS, Galea DES. Provas de nomeação e imitação como instrumentos de diagnóstico do transtorno fonológico. Pró-Fono. 2006;18(3):303-12. 
Anexo 1. Figuras que compõem o instrumento de avaliação para análise acústica (IAFAC)
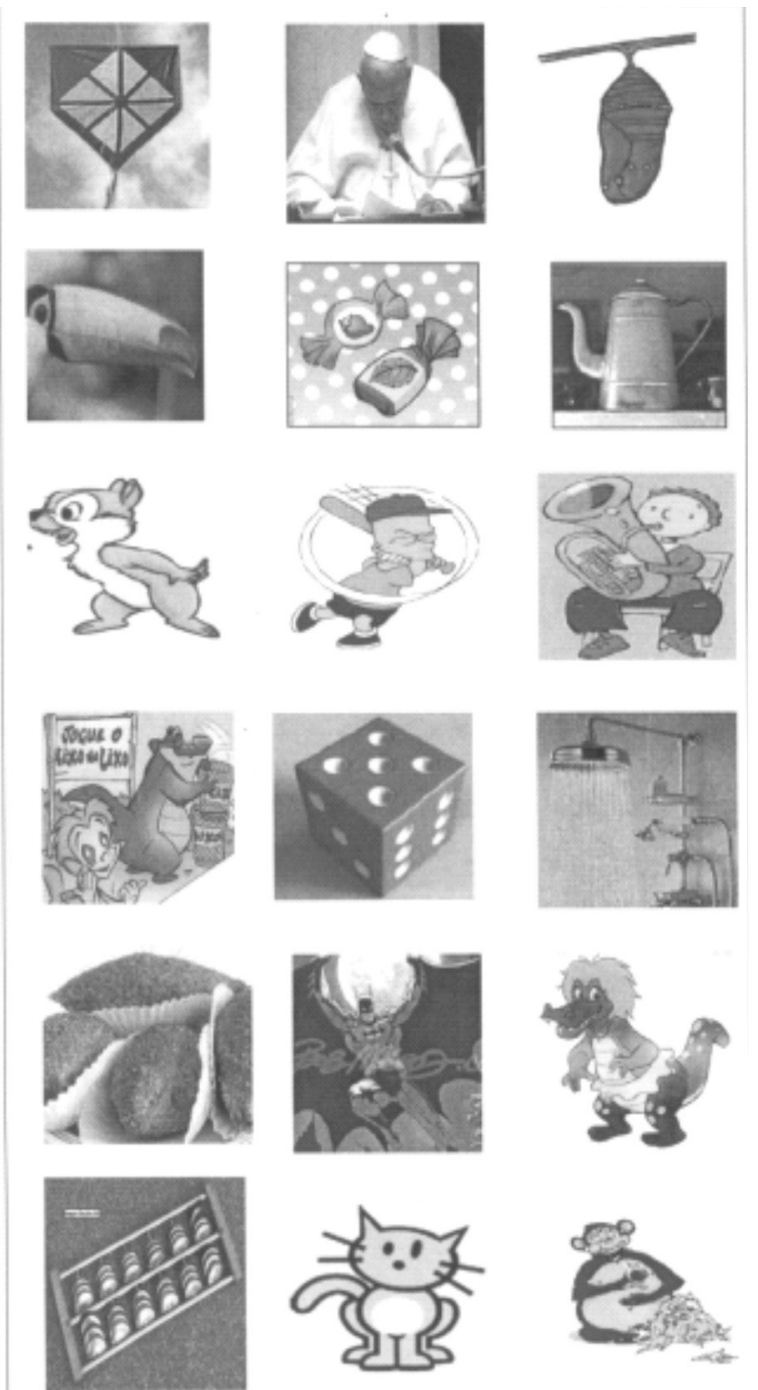
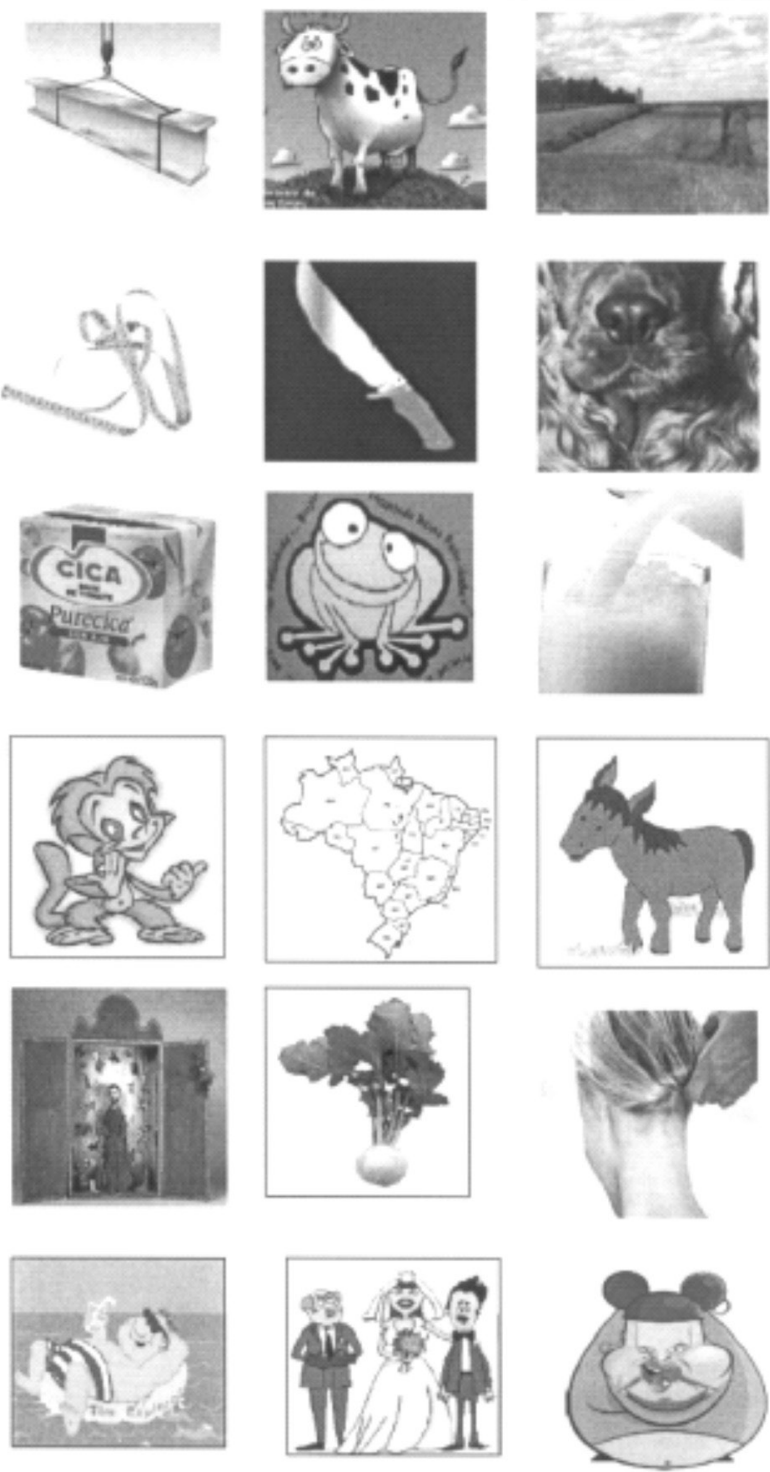


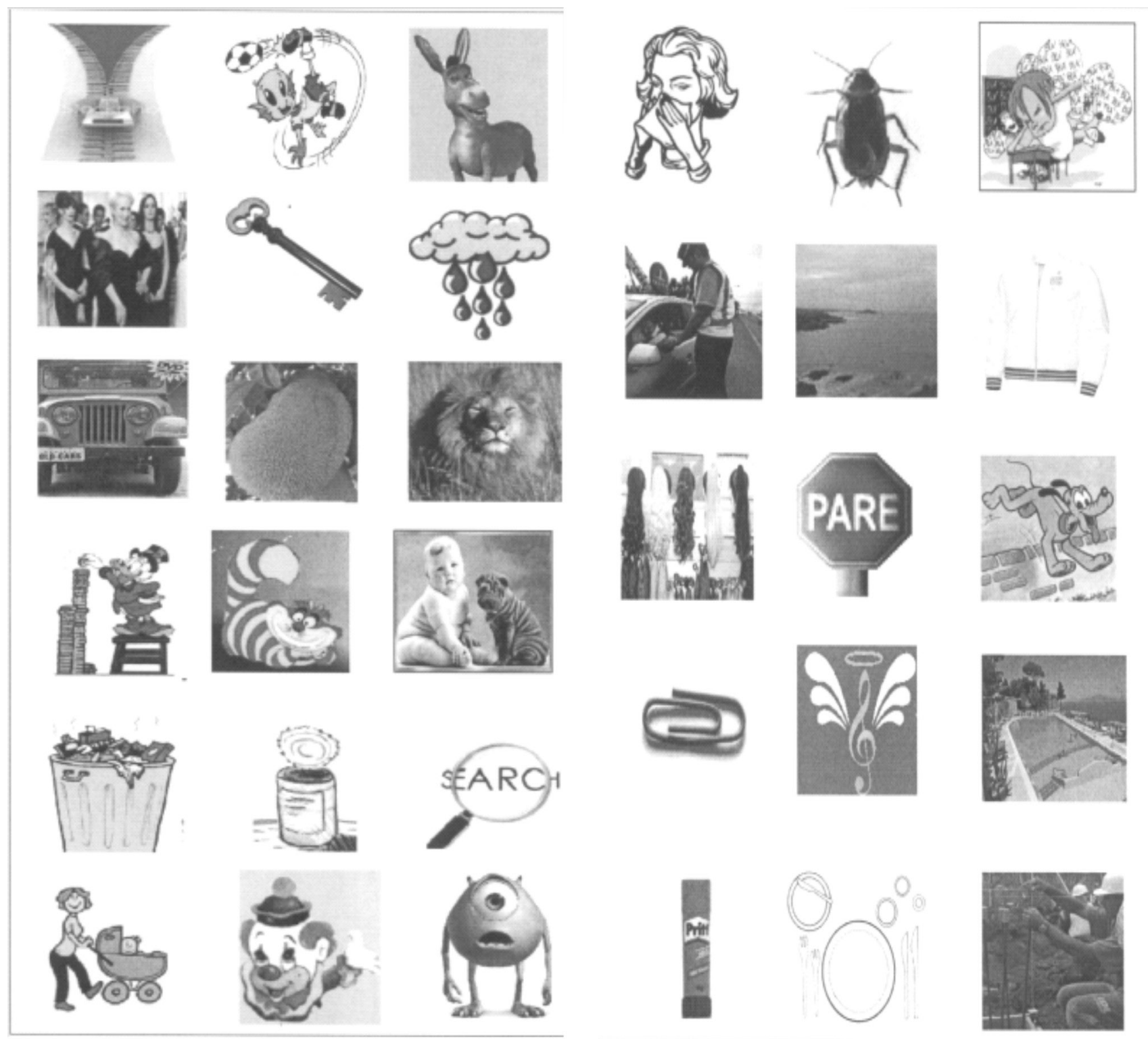



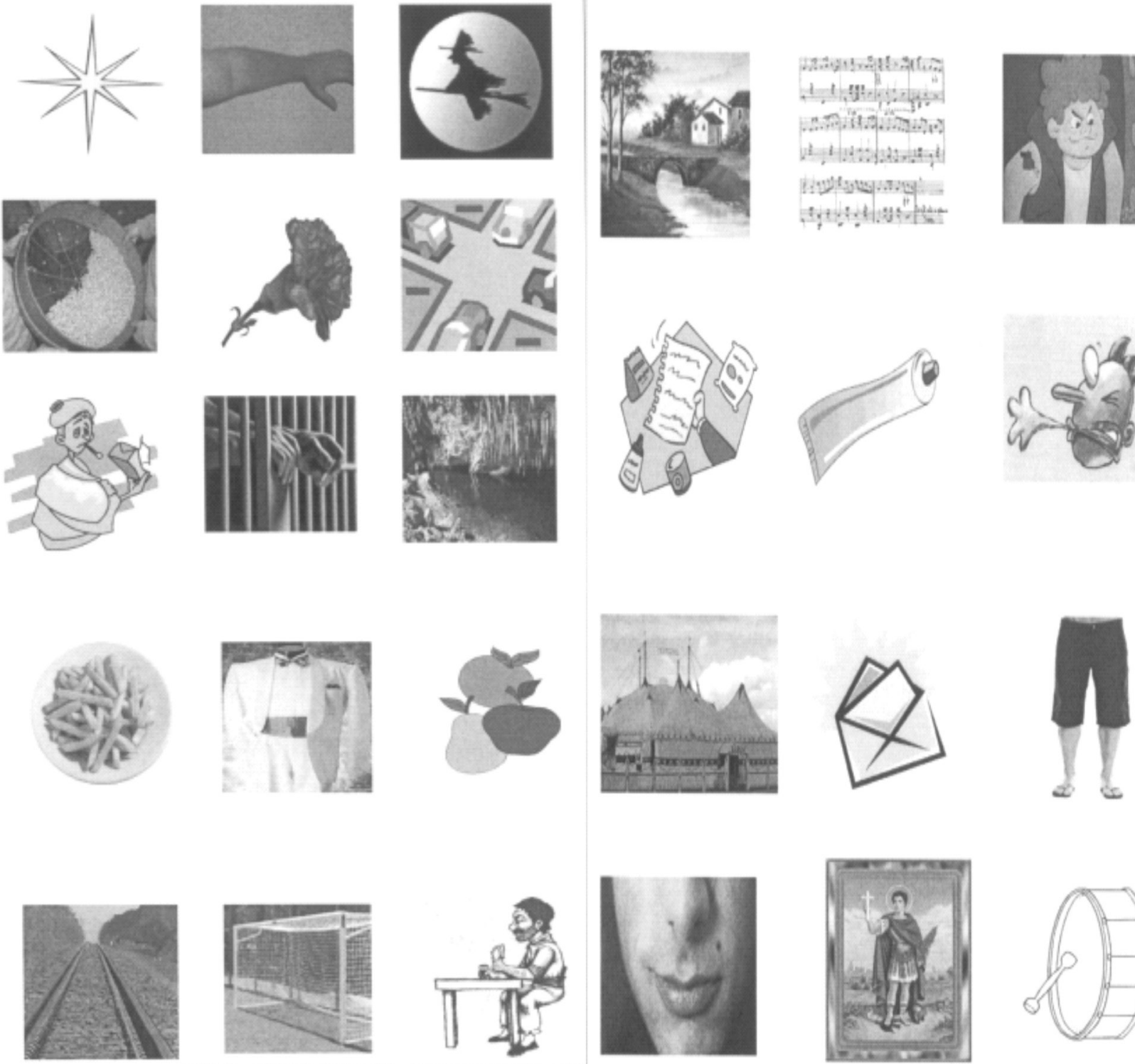

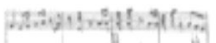

1, 1,410,

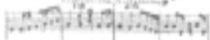

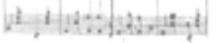

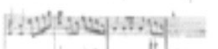

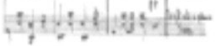
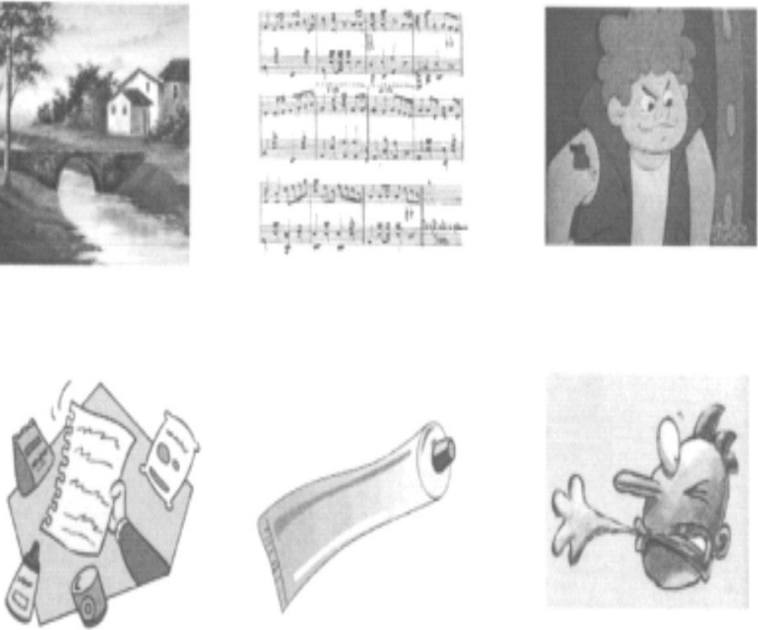